\title{
NIETZSCHE Y LA IMAGEN ¿EL MUNDO VERDADERO SE HA CONVERTIDO EN UNA FÁBULA?
}

Nietzsche and the Image. Has the real world become in a fable?

\author{
Federico Vercellone \\ Universidad de Turín
}

\begin{abstract}
Resumen: En este texto el concepto que tiene Nietzsche de la imagen es presentado tal y como evolucionó con el desarrollo de su filosofía. En sus primeros escritos, sobre todo en El nacimiento de la tragedia, lo que se pone de relieve es la imagen que se concibe como un símbolo artístico, como una expresión de la naturaleza y no como una representación del mundo. Si tenemos en cuenta el desarrollo del pensamiento de Nietzsche, podemos ver que en el último periodo tenemos una concepción de la imagen que depende de la idea de perspectiva, con un tipo de imagen que se concibe como una representación. La imagen como una representación ha perdido toda relación positiva con el mundo y es un factor importante en la «voluntad de poder». La imagen coincide ahora con el «fin del arte» hegeliano.
\end{abstract}

Palabras clave: imagen - perspectiva - voluntad de poder

ABSTRACT: In this text Nietzsche's concept of image is presented as it evolved with the development of his philosophy. In his early writings, particularly in The Birth of the Tragedy, what comes out is the image which is conceived as an artistic symbol, as an expression of nature and not as a representation of the world. If we consider the development of Nietzsche's thought, we can see that in the last period we have instead a conception of the image that depends on the idea of perspective, with a kind of image which is conceived as a representation. Image as a representation has lost every positive relationship to the world and is an important factor in the «will to power». The image now coincides with the Hegelian «end of art».

Keywords: Image - Perspective - Will to Power

\section{NIETZSCHE Y LA IMAGEN}

Cuando se aborda el tema «Nietzsche y la imagen» nos topamos con un itinerario muy complejo, que recorre toda la obra de Nietzsche. Se describe un largo periplo que recorre todo el mundo de la imagen. Un itinerario que tiene que ver muy de cerca con la sentencia hegeliana sobre «el fin del arte».

Es un periplo que comienzo con las dimensiones simbólicas que la imagen adquiere en la obra del primer Nietzsche, y sobre todo en la obra que abre en sentido más pleno el itinerario filosófico del joven profesor de la universidad de Basilea, El nacimiento de la tragedia a partir del espíritu de la música. Se pasa aquí de la dimensión simbólica que la imagen asumió en el romanticismo 
alemán, y en especial en un autor como Friedrich Creuzer, una dimensión que Nietzsche intenta con todos sus esfuerzos renovar, a la trágica derrota que Nietzsche define en términos eufóricos como «voluntad de poder».

Para comenzar, es conveniente definir los objetivos que Nietzsche se fija en El nacimiento de la tragedia. Se trata en gran medida, y declaradamente, de objetivos polémicos. Como es bien conocido, el objeto de la polémica es la cultura moderna, la «cultura histórica» a la que Nietzsche contrapone el modelo de la Bildung antigua.

Ahora bien, resumiendo muy sintéticamente la cuestión, Nietzsche en la primera fase de su itinerario teórico se propone:

a) Mostrar que la cultura moderna, la cultura histórica, se ha trasformado en una cultura de la mera representación. Se trata de una cultura que ha abocado en una trágica derrota por lo que respecta a las cualidades mitopoiéticas. Se trata, además, como tendremos ocasión de ver mejor más adelante, de una cultura desenraizada, una cultura de la máscara ${ }^{1}$, de la «mascarada universal», del «carnaval en gran estilo». Desde este punto de vista se trata de una cultura de la «muerte del arte», de una cultura estetizada que ya no ve en el arte el culmen de una civilización como ocurría en cambio en la época de la cultura griega de la edad trágica.

b) Mostrar que la cultura antigua, la cultura griega de la «edad trágica de los griegos» era en cambio una «cultura expresiva». Con «cultura expresiva» nos referimos a una cultura alimentada por un contenido infinito, que proviene de la naturaleza y culmina en el arte. Es una cultura con rígidos límites que, sin embargo, también gracias a este encerramiento, consigue desarrollar en su interior una inmensa potencia simbólica.

La antítesis antiguo/moderno puede así definirse en torno a la alternativa entre símbolo y representación, o también de enraizamiento y desenraizamiento. Si la cultura antigua determina en efecto la pertenencia a un mundo y sus límites, la moderna determina un profundo desenraizamiento que Nietzsche al principio lo resalta como puramente negativo, y luego lo asume y hace suyo.

Se trata de una revalorización imprevista de lo moderno, que provoca una inversión de juicio con respecto a él. En particular, los límites que antaño parecían constituir un elemento que avalaban esta cultura se convierten, bajo la mirada de Nietzsche, en un obstáculo para un desarrollo más alto.

\section{EL NACIMIENTO DE LA TRAGEDIA}

En El nacimiento de la tragedia uno parece encontrarse en un universo dominado por una rígida bipartición, por la cual el mundo de la imagen, o mejor de la representación, le compete a Apolo, mientras que la esencia de lo dionisíaco es musical. En realidad, mirándolas con cuidado, las cosas son más complejas en cuanto que en su originario manifestarse el universo dionisíaco está dotado de una inmensa potencia expresiva que aflora en superficie según modalidades simbólicas. Nietzsche afirma:

1. Cf. G. Vattimo, Il soggetto e la maschera. Nietzsche e il problema della liberazione, Milano: Bompiani, 1974. 


\begin{abstract}
Ahora el ser de la naturaleza debe expresarse simbólicamente; es necesario un nuevo mundo de símbolos, se requiere de golpe todo el simbolismo corporal, no solo el simbolismo de la boca, del rostro, de la palabra, sino el gesto pleno del baile, que mueve rítmicamente todos los miembros. Acto seguido, las otras fuerzas simbólicas, las de la música, crecen de repente con vehemencia, convertidas en rítmica, dinámica y armonía. Para captar este desencadenamiento global de todas las fuerzas simbólicas el ser humano tiene que haber llegado ya a aquella altura de la autoenajenación que quiere expresarse simbólicamente en aquellas fuerzas: ial servidor ditirámbico de Dioniso, por tanto, solo lo entienden sus iguales! ${ }^{2}$.
\end{abstract}

Estamos aquí tratando con una modalidad expresiva que pertenece ante todo a la naturaleza y que se transmite al hombre. Se trata de una modalidad originaria de significación simbólica, que Nietzsche hereda en parte de la distinción de Friedrich Creuzer entre un símbolo «místico» y un símbolo "plástico», es decir, entre una simbólica que deriva de una modalidad originariamente expresiva de la naturaleza y otra que en cambio se remonta a una significación arbitraria producida por la casta sacerdotal. Se trata por tanto de una dimensión de la imagen en la cual no se desarrolla una representación subjetiva del mundo. Más en general, no se trata del universo de la representación cual correlato subjetivo del mundo percibido. El esquema sujeto/objeto nada tiene que ver aquí. Sino que se trata más bien de una pertenencia al mundo en imagen. Esta se realiza para Nietzsche a través de la tragedia. Justamente gracias a esta prerrogativa suya, la tragedia puede perfilarse como el culmen de una cultura, es decir, como la forma suprema en la cual ella organiza su propio rememorar. El esquema más profundo del argumento nietzscheano es propiamente de procedencia goethiana. Se trata en efecto de una cultura enraizada en la naturaleza, que organiza mediante un movimiento transfigurador sus formas, allí donde estas formas constituyen también un movimiento que recoge, mantiene y articula el rostro doliente de la naturaleza intacta. Como se sabe, la tragedia vive gracias a un progresivo movimiento de trasposición-trasfiguración de la verdad dionisíaca en la apariencia apolínea. El espectador trágico que idealmente representa la masa dionisíaca se refleja en el coro, mientras el coro se refleja en la escena. Nietzsche dice a este respecto:

De acuerdo con este discernimiento estamos autorizados a llamar al coro, en su estadio primitivo en la tragedia primordial, una autorreverberación del ser humano dionisíaco: este fenómeno puede ser aclarado de forma óptima mediante el proceso que sufre el actor, el cual, teniendo verdadera aptitud, ve flotar ante sus ojos de una manera palpablemente perceptible su imagen del personaje que él mismo está representando. El coro de sátiros es ante todo una visión que tiene la masa dionisíaca, como el mundo del escenario es, a su vez, una visión que tiene ese coro de sátiros: la fuerza de esta visión es bastante poderosa para hacer que la mirada se vuelva opaca e insensible ante la impresión de la «realidad», ante los seres humanos que cuentan con formación, situados circularmente en las filas de asientos ${ }^{3}$.

Es evidente que, en este marco, el aspecto mítico-ritual de la tragedia prevalece sobre la autonomía de la escena artístico. En este marco la tragedia se

2. NT $\$ 2$, OC I 288-289 (KSA I 30).

3. NT $\mathbb{8}$, OC I 309 (KSA I 58-59). 
propone una especie de crítica inmanente de la moderna conciencia estética y de la autonomía del arte. Allí donde el arte autónomo constituye el modelo de una cultura también fundada en la imagen. Pero ya no en la imagen como símbolo, sino en la imagen como representación. Como veremos más adelante, la crítica del joven Nietzsche a la modernidad no se funda en la alternativa mito/logos, sino en la de imagen/símbolo e imagen/representación. Esta es la clave que nos permite conectar e interpretar como un unicum la primera fase del itinerario teórico nietzscheano a través de las tres obras más significativas de este período: El nacimiento de la tragedia, Sobre la utilidad e inconvenientes de la historia para la vida y Sobre verdad y mentira en sentido extramoral. Es un itinerario que, condenando los errores de la conciencia estética, condena la cultura moderna en su conjunto, y viceversa. La cultura moderna es entendida e interpretada sobre la base del carácter modélico de la cultura griega que se funda en la tragedia, como una cultura estetizante, como una cultura de la «mala» representación.

Pero procedamos con orden para distinguir los modos en los que se articula la tragedia. Como es sabido, según Nietzsche, la tragedia se origina en una esfera sacrificial, la del despedazamiento y el resurgimiento desde los mismos miembros de Dioniso despedazado por los Titanes:

El único Dioniso verdaderamente real se manifiesta en una pluralidad de figuras, con la máscara de un héroe que lucha, y, por así decirlo, prisionero en la red de la voluntad individual. Tal y como ahora habla y actúa ese dios que se manifiesta, se asemeja a un individuo que comete errores, siente ansias y sufre: y el que se manifieste en general con esta precisión y esta claridad épicas es el efecto del Apolo intérprete de sueños, el cual mediante aquel fenómeno de tipo metafórico le interpreta al coro su estado dionisíaco. En verdad, sin embargo, aquel héroe es el Dioniso sufriente de los misterios, aquel dios que experimenta en sí los sufrimientos de la individuación, del que mitos maravillosos cuentan que, siendo niño, fue despedazado por los titanes, y que en ese estado es venerado desde entonces como Zagreo ${ }^{4}$.

Es por tanto Apolo el que se convierte en el intérprete de Dioniso. Es gracias a los rasgos épicos de la figura apolínea que Dioniso puede revelarse. La verdad dionisíaca se adueña por su parte de toda la esfera del mito y la convierte en su instrumento:

La verdad dionisíaca se posesiona del ámbito completo del mito como simbolismo de sus conocimientos [...] ¿Cuál fue la fuerza que liberó a Prometeo de su buitre y que transformó el mito en vehículo de la sabiduría dionisíaca? La fuerza del tamaño de la de Heracles de la música: como tal, y habiendo alcanzado en la tragedia su fenómeno supremo, sabe interpretar el mito con un nueva y profundísima significatividad ${ }^{5}$.

Precisamente, cuando se abre el camino hacia el mito es cuando los aspectos terroríficos relacionados con el culto dionisiaco se dulcifican, se pliegan a la articulación épico-narrativa. La transfiguración en la apariencia no constituye sin embargo para Nietzsche simplemente un volver la mirada del rostro terrible de la

4. NT $₫ 10$, OC I 318 (KSA I 71-72).

5. NT $\$ 10$, OC I 319-320 (KSA I 73). 
naturaleza virgen. $\mathrm{Al}$ mismo tiempo tiene que ver con una obra de rememoración de aquello que se transfigura. A través de la obra transfiguradora de la apariencia, la tragedia se hace memoria, se constituye más bien como la memoria por excelencia de una cultura que ella contribuye a fundar y que de ella toma el nombre. La tragedia se hace memoria del sacrificio de aquel único Dioniso que, en la ausencia de la articulación mítica, se vería obligado a un silencio turbulento.

Los ropajes del mito cubren por lo tanto el desmembramiento del único Dioniso, el verdadero y único protagonista de la escena griega. Cuando se multiplican los rostros heroicos, se detiene la memoria que instituye una cultura y constituye el trasfondo imprescindible de ella. El evento originario es asumido y transfigurado en la esfera de la apariencia apolínea; y esta se hace de esa manera intérprete de una laceración que amortigua el impacto de lo terrible. Y es esta transfiguración interpretadora la que da lugar a la escena trágica: «El coro de los sátiros es ante todo una visión de la masa dionisiaca, como a su vez el mundo de la escena es una visión de este mundo de sátiros» ${ }^{6}$.

La tragedia llega de este modo a constituirse en el horizonte infinito de la apariencia. $Y$ cuando esta última se multiplica, viene a garantizar la rememoración y su continuidad; se podría incluso afirmar que la tragedia es el paradigma de una cultura en cuanto que constituye el tejido rememorante de esta última. Pero la misma continuidad de lo trágico es finalmente garantía de la infinitud de la apariencia; se trata del horizonte inagotable de la interpretación que cambia en la representación simbólica el rostro terrible de la naturaleza virgen. Dentro de este frágil horizonte lo trágico nietzscheano revela su naturaleza más profunda: no tiene tanto que ver con el reconstituirse «inactual» de un horizonte hegelianamente mantenido unido por el ethos, sino con la continuidad del mythos, de aquel horizonte narrativo que instituye la existencia, del cual la modernidad, según la denuncia de Nietzsche en la segunda Intempestiva, parece que se olvida. Eurípides y Sócrates representan, desde este punto de vista, un tránsito al mismo tiempo histórico, dentro de la cultura griega, y simbólico, en dirección de la modernidad madura.

Y de tal manera esto es así, que cuando Nietzsche vuelve a dar este salto en la segunda Consideración intempestiva lo hace a todos los efectos como «alumno de épocas pasadas, en particular de la griega». Y el tránsito de lo antiguo a lo moderno en el fondo ha llegado paradójicamente al interior de la cultura griega. La cultura racional impuesta por Sócrates y, por su mediación, por Eurípides, es a todos los efectos un preludio de cuanto sucede modernamente.

Para aclarar esta cuestión podremos decir que Apolo, sin la contribución de Dioniso, se corrompe, decae en cuanto a sus posibilidades mitopoéticas y simbólicas, y se convierte en el emisario de una significación carente de plasticidad que se ha reducido a sí misma al plano de una representación exangüe. Nos encontramos de pronto, pero no demasiado, en un ámbito de aquella cultura estetizada de la que se hablaba antes. Es el plano en el que se puede hablar de un «fin» o «muerte del arte» nietzscheano 7 . Es el plano de un arte estetizado que no coincide ya con la vida, y que no está ya en condiciones de proporcionar una identidad con la cultura y con los individuos que viven en su interior. Por el contrario, se

6. NT $\$ 8$, OC I 309 (KSA I 58-59),

7. Cf. C. Gentili, «Morte dell'arte' e 'Morte di Dio'. Confronti testuali e relazioni concettuali», en M. C. Fornari (ed.), Nietzsche. Edizioni e interpretazioni, Pisa: ETS, 2006, pp. 179-192. 
trata, precisamente sobre este plano, de una cultura también ella estetizada que no saca ya provecho de la expresión simbólica, sino que confina la imagen sobre el plano de la mera representación. El hombre moderno, que vive en la cultura histórica, es un individuo que puede identificarse en todo pasado, que puede avanzar arbitrariamente entre los bastidores de la historia. Pero la identidad que busca es de naturaleza fantasmática, es en realidad aquella que una y otra vez se le escapa. Como es bien conocido, Nietzsche escribe a este respecto:

Así, el individuo se vuelve tímido e inseguro y ya no puede creer en sí: se hunde en sí mismo, en lo interior, lo cual en este caso no significa otra cosa que el cúmulo heterogéneo de lo aprendido que no obra hacia fuera, de lo enseñado que no se torna en vida. Considerando lo exterior, se nota que la expulsión de los instintos por la historia ha convertido a los seres humanos casi por entero en abstractis y sombras: nadie expone ya su persona, sino que se disfraza de hombre formado, de erudito, de poeta o de político. Cuando uno toca tales máscaras, creyendo que toman en serio lo que son y no hacen meramente un juego de poses - puesto que todas aparentan seriedad - , se queda de pronto con nada más que un montón de trapos y retazos multicolores en las manos ${ }^{8}$.

Se trata, según la denuncia nietzscheana, de un saber que erradica los instintos, que renuncia a las propias raíces «naturales», que no deja espacio a aquel profundo sentimiento unificador que, en los griegos, permite el surgir de una cultura que vale todavía para el presente como un modelo supremo. Un modelo supremo que no se entiende sin embargo como un paradigma estilístico estable y reproducible. Se trata más bien de la idea, dominada grandiosamente por la figura de Goethe, de que «la cultura es una physis nueva y perfeccionada, sin interior ni exterior, sin fingimiento ni convencionalismo, la cultura como una luminosa armonía entre el vivir, el pensar, el aparentar y el querer»"

Es una cultura que no está sometida al perspectivismo moderno, a la omnipotente pretensión de hacer propio todo pasado, de pasar sin fricciones a través de las escenas de la historia. Es una ilusión que, como es bien sabido, produce un debilitamiento de la personalidad del hombre moderno, introduce en su interior una fractura lacerante entre interior y exterior; mirando hacia delante y remitiéndonos al diálogo entre el conde de Yorck von Wartenburg y Dilthey, la cultura histórica se perfila ya a los ojos de Nietzsche como una cultura "ocular», íntimamente ligada al perspectivismo. Nietzsche escribe a este respecto:

Cierto predominio de historia puede dar lugar a todo esto, como hemos visto, por cuanto al modificar constantemente las perspectivas del horizonte y eliminar la atmósfera envolvente ya no le permite al ser humano sentir y obrar abistóricamente $^{10}$.

De este modo se llega al éxito extremo del socratismo moderno encarnado por la cultura histórica, al «fin del arte del lado de su destino», aquel destino por el que constituye el centro viviente de una cultura. Se propone ahora una

8. UPH $\$ 5$, OC I 717 (KSA I 296-297).

9. UPH $₫ 10$, OC I 748 (KSA I 355 ).

10. UPH $\$ 9$, OC I 742 (KSA I 344). 
cultura estetizada que se autoproduce como un universo ilusionista de máscaras carentes de sustancia viviente, como una especie de proliferación enorme de perspectivas subjetivamente fundadas, que finalmente tomará el nombre de «voluntad de poder». La metaforicidad incandescente que nutría la palabra trágica llega a apagarse ahora. La naturaleza, como hemos dicho hace un momento, ya no nutre a nuestra cultura. Por el contrario, tenemos que ver con un proceso enorme de antropomorfización del mundo que se agrupa en torno al binomio desmitización/objetivación.

Es crucial en este marco Verdad y mentira en sentido extramoral, en el que este proceso se perfila de una manera muy perspicaz. La nivelación de las posibilidades metafóricas, artísticas en sentido amplio, en sentido propio mitopoéticas del lenguaje, responde a exigencias de economía de la comunicación. Coincide con la necesidad de una comunicación unívoca y privada de ambigüedad que favorezca un intercambio interhumano eficaz y privado de fricciones. Como veremos más adelante, este sueño de objetivar el mundo, de plegarlo definitivamente a la subjetividad produciría en última instancia una ilusión más bien trágica de la ilusión trágica originaria. Nietzsche escribe a este respecto en Verdad y mentira en sentido extramoral:

El investigador de tales verdades tan solo busca, en el fondo, la metamorfosis del mundo en los seres humanos; lucha por comprender el mundo como algo humano, y lo mejor que puede lograr en esa lucha es un sentimiento de asimilación. [...] Solo mediante el olvido de ese primitivo mundo de metáforas, solo mediante el endurecimiento y la petrificación de una masa de imágenes que brota originariamente en candente fluidez de la capacidad primordial de la fantasía humana, solo mediante la invencible creencia en que este sol, esta ventana, esta mesa, sean una verdad en sí, en una palabra, gracias solamente a que el ser humano se olvida de sí mismo en cuanto sujeto y, en particular, en cuanto sujeto artísticamente creador, vive con cierta calma, seguridad y coherencia; si pudiera salir, aunque solo fuese un instante, fuera de los muros de la cárcel de esa creencia, se acabaría en seguida su «autoconciencia» ${ }^{11}$.

La otra cara necesaria de la objetivación del mundo es su extrema subjetivación. Es esta la paradoja nietzscheana que nos introduce por lo demás en el interior de su definición de nihilismo, que es también la que continua hoy en día siendo válida como paradigma de este concepto y de su vasta fenomenología cultural. Se trata de un reconocimiento que tiene diversos pasos dentro de la obra de Nietzsche. En Humano, demasiado humano se perfila por ejemplo la idea de que la ciencia es la que ha de concurrir a la obra del desvelamiento, a revelarnos que todo lo que resulta como objetivo no es otra cosa que el resultado de una objetivación, y por tanto en última instancia no es otra cosa que una ficción subjetiva:

Porque desde hace miles de años, hemos contemplado el mundo con pretensiones morales, estéticas, religiosas, con una ciega inclinación, pasión o temor, y nos hemos cogido nuestra borrachera de impertinencias del pensamiento ilógico, es por lo que este mundo se ha vuelto poco a poco tan maravillosamente abigarrado, terrible,

11. VME, OC I 611 (KSA I 364-365). 
profundo de sentido, lleno de alma; ha recibido colores, pero es que hemos sido nosotros los coloristas: la inteligencia humana, a causa de los apetitos humanos, de las afecciones humanas ha hecho aparecer esta "apariencia» y ha transportado a las cosas sus concepciones erróneas fundamentales [...] De todas estas concepciones, la marcha constante y penosa de la ciencia, celebrando finalmente una vez más su mayor triunfo en una historia de la génesis del pensamiento, logrará de una manera definitiva, cuyo resultado podría conducir a esta proposición: lo que llamamos actualmente el mundo es el resultado de una multitud de errores y de fantasías, que nacieron poco a poco en la evolución de conjunto de los seres organizados, se entrelazan en su crecimiento y llegan ahora a nosotros por herencia como un tesoro acumulado de todo el pasado; como un tesoro, pues el valor de nuestra humanidad reposa sobre esto. De este mundo de la representación la ciencia severa puede efectivamente librar solo en una medida mínima - aunque esto, por otra parte, no sea de desear -, por el hecho de que no pude romper radicalmente la fuerza de los hábitos antiguos de sentimiento; pero puede iluminar muy progresivamente y paso a paso la historia de la génesis de este mundo como representación, y elevarnos, al menos por unos instantes, por encima de todo el proceso ${ }^{12}$.

Hasta este punto, Nietzsche ha dado un paso fundamental en el progreso de su diagnóstico. Pero todavía no ha dado el paso decisivo. Esto tendrá lugar años después, cuando Nietzsche tomará conciencia de aquella pérdida del centro que está bajo el nombre de la «muerte de Dios». Con buenas razones se puede retener que esta pérdida del centro tiene que ver con la pérdida del centro focal de la mirada, con el retroceso del centro perspectivista. El anuncio de la «muerte de Dios» se acompaña de hecho con la idea de la pérdida de todo horizonte:

¿Quién nos dio la esponja con la que secar todo el horizonte? ¿Cómo hemos conseguido desprender a esta tierra de las cadenas de su sol? ¿Hacia dónde nos movemos ahora? ¿Lejos de todos los soles? ¿No es el nuestro un eterno precipitarnos? ¿Hacia atrás, de lado, hacia delante, hacia todas partes? ¿Existe aún un arriba y abajo? ¿Acaso no estamos vagando como a través de una nada infinita? ${ }^{13}$.

Gracias a este paso es como alcanzamos a captar la naturaleza más profunda del punto de vista de Nietzsche. Podríamos resumir las cosas, y todo el proceso al que hemos asistido hasta ahora, como sigue. La pérdida de una significación simbólica ha producido la objetivación de aquello que llamamos mundo. Con la objetivación del mundo se acompaña la conciencia paradójica pero consecuente de la naturaleza supremamente subjetiva de su ser. El éxito de esta subjetivación es que toda mirada sobre el mundo constituye un punto de vista sobre él. Y la transformación de la mirada sobre el mundo en un punto de vista hace de este último una mera representación. Pero todo eso no basta. En última instancia tiene que llegar a faltar también el foco de la mirada. Si el foco de la mirada estuviese comúnmente orientado llegaríamos en el fondo a encontrarnos sobre el plano trascendental, que no tendría nada de trágico o de inquietante. Si nos ponemos de acuerdo en cómo vemos, veremos todos en el fondo del mismo modo. Sobre esta vía, en sentido kantiano muy lato, la objetividad no se perdería, sino que se reduciría a un

12. MA I $\$ 16$.

13. $\mathrm{FW} \$ 125$. 
vínculo convencional. Esto hace emerger en toda su potencia trágica y nihilista el diagnóstico nietzscheano. Si los puntos de vista sobre el mundo se multiplican con la ausencia de un centro, necesariamente disminuye también la objetividad como acuerdo convencional entre los sujetos que ven del mismo modo el mismo mundo. Esto lleva al primer plano la naturaleza esencial de la representación como pérdida del mundo. La representación se revela como una pérdida del mundo allí donde disminuye también la objetividad última, la de la mirada perpectivistamente orientada. Pero esto solo ilustra la naturaleza más profunda de esta mirada. Muestra que la mirada fundada sobre la representación es una mirada nihilista. Es el factor central de aquel proceso de disolución del centro por el que «el 'mundo verdadero' terminó convirtiéndose en una fábula».

Según el diagnóstico de Hans Belting, en muchos sentidos es el destino de la mirada occidental. Pero sobre esto hablaremos en breve. Es importante, por el contrario, subrayar a partir de ahora cómo ha sido precisamente esta toma de conciencia la que orienta a Nietzsche hacia la elaboración de la noción de «voluntad de poder». Esta no constituye otra cosa que la madurez consumada de una mirada privada de centro perspectivista. Nietzsche define todo este proceso como el proceso en el que la voluntad de poder como arte toma forma. Pero podemos decir mejor de la voluntad de poder como «fin del arte», de un arte que va hacia su ocaso en cuanto concierne a su estatuto mítico, simbólico, veritativo.

En uno de sus fragmentos póstumos más famosos, al recapitular su itinerario desde El nacimiento de la tragedia, Nietzsche afirma la total coherencia de este. Pero se trata de una coherencia ambigua, que habría que poner en cuestión. Sin duda, lo que es definido como arte sigue manteniendo una prioridad metafísica dentro del planteamiento de la obra de Nietzsche. Pero el estatuto de lo que es definido como arte en el ínterin ha sido modificado. Pues si en El nacimiento de la tragedia, se trata de la estructuración simbólica de la apariencia estética que nace del seno infinito de la naturaleza intacta, ahora se trata de una forma nihilista de la apariencia, de la apariencia como ilusión, de la moderna apariencia estética. Es una apariencia que produce mundos, mientras que la precedente estaba alimentada por el mundo. O más bien, es una apariencia que produce perspectivas distintas sobre el mundo que no consiguen hallar entre ellas ningún acuerdo. Escribe Nietzsche:

La concepción del mundo que se encuentra en el trasfondo de este libro es singularmente siniestra y desagradable: de los tipos de pesimismo que hasta ahora se han conocido, ninguno parece que haya alcanzado ese grado de malignidad. Aquí falta la contraposición entre un mundo verdadero y un mundo aparente: solo hay un único mundo, y ese es falso, cruel, contradictorio, seductor, carente de sentido... Un mundo así constituido es el mundo verdadero... Nosotros necesitamos la mentira para vencer esa realidad, esa «verdad», esto es, para vivir... Que la mentira es necesaria para vivir, esto incluso forma parte de ese carácter temible y problemático de la existencia...

La metafísica, la moral, la religión, la ciencia - entran en consideración en este libro solo como formas diversas de la mentira: con su ayuda se cree en la vida. «La vida debe inspirar confianza»: la tarea, así planteada, es enorme. Para resolverla, el ser humano ha de ser ya por naturaleza un mentiroso, ha de ser más aún que cualquier otra cosa, un artista... Y no hay duda de que lo es: metafísica, moral, religión, ciencia - solo son criaturas de su voluntad de arte, de mentira, de 
huida ante la «verdad», de negación de la «verdad». Esta capacidad misma, gracias a la cual él viola la realidad con la mentira, esta capacidad artística par excellence del ser humano - la tiene en común con todo lo que existe: él mismo es, ciertamente, una porción de realidad, de verdad, de naturaleza - él mismo es incluso una porción de genio de la mentira...

Que el carácter de la existencia se desconoce — la más profunda y la suprema intención secreta $<$ de la $>$ ciencia, la religiosidad, la artisticidad. No ver nunca muchas cosas, ver falsamente muchas cosas, añadir muchas cosas a las que se ven... iOh, cuán inteligente se es en estados en que se está muy lejos de tenerse por inteligente! El amor, el entusiasmo, «Dios» — iuna sarta de finuras del extremo autoengaño, una sarta de seducciones para vivir! En instantes en que el ser humano resulta el engañado, en que vuelve a creer en la vida, en que se ha superado en astucia a sí mismo: ioh, cómo eso entonces lo hincha! iQué delicia! iQué sentimiento de poder! iCuánto triunfo artístico en el sentimiento de poder!... ${ }^{14}$.

Se ve que en este libro el pesimismo, digámoslo con mayor claridad, que el nihilismo está considerado como la verdad ${ }^{15}$.

En este marco, el arte puede convertirse efectivamente en el modelo de la voluntad de poder: la voluntad de poder, en cuanto arte, se convierte por su parte en el modelo metafísico supremo, una libre producción simbólica que desemboca en una libre producción de mundos. Una producción de mundos a la que en realidad la falta su objetivo, pues le falta $e l$ mundo. Es decir, no consigue coagularse en torno a ese centro perspectivista que ha caído definitivamente después de la «muerte de Dios». A pesar de todo esfuerzo o esperanza por parte de Nietzsche, sobre la base del perfilarse de las múltiples perspectivas no es posible extraer ese coagulo que se llama mundo. Pues este presupondría la existencia de ese centro, de ese foco en la mirada que debe darse a priori y que a posteriori no puede ser reconstruido. A este propósito Nietzsche parece caer en una patente contradicción. Él escribe a este propósito: «Todo centro de fuerza tiene su perspectiva para el resto entero, es decir, su valoración enteramente determinada, su tipo de acción, su tipo de resistencia [...] y el 'mundo' no es más que una palabra para el juego conjunto de esas acciones» ${ }^{16}$.

De esta manera, el itinerario nietzscheano llega a una conclusión coherente. La naturaleza ilusoria de la cultura histórica se revela ahora, ya no de manera negativa sino positiva, como la clave fundamental de una visión del mundo. Por otra parte, este universo estetizado, pretendidamente artístico, condena al arte a morir en el ámbito del ilusionismo más universal. El arte estetizada, en la cual Hegel, por buenas razones, había visto el "fin del arte», se convierte aquí en un modelo tan potente como para convertirse en principio metafísico supremo. El modelo representativo de la visión, sobre el que Hans Belting ha llamado recientemente la atención, descubriendo en él el modelo de la visión occidental, se determina, a lo largo del desarrollo del pensamiento nietzscheano, como un modelo nihilista pero muy influyente y capaz de orientarse (o perderse) por el mundo ${ }^{17}$.

14. FP IV 491-492: 11[415].

15. FP IV 697: 17[3].

16. FP IV 601-602: 14[184].

17. Cf. H. Belting, Florenz und Bagdad. Eine westöstliche Geschichte des Blicks, München: Beck, 2008. 
Esto nos lleva, por otra parte, a un panorama que nos sigue siendo familiar: es el de un intenso deseo de las perspectivas que querrían coagularse en una forma que no consiguen encontrar. Es un intenso deseo producido por las miradas paralelas que querrían encontrarse en un punto de fuga que, una y otra vez, se sustrae y desaparece. Esto describe acaso también nuestro mundo, en el cual las pretensiones de verdad se flanquean unas a otras, produciendo el más inquietante y ficticio de los rostros del pluralismo: el de la multiplicidad de las perspectivas que no consiguen encontrarse en torno a punto medio. Así que cada una de ellas alberga una pretensión de verdad tan absoluta cuanto infundada por la imposibilidad de comparación. Esto es el rasgo esencial de la violencia. Pues de la comparación imposible se genera el intento extremo y más desesperado de crear el contacto con el otro: la ceguera de la lucha. Quizás también a este respecto, nuestro tiempo, que entre otras cosa ha podido ver un renacimiento tan grande de las guerras de religión, es hijo de la trágica enseñanza de Friedrich Nietzsche. 